\title{
Patient Characteristics Profile and Pap Smear Examination Results at Pasar Minggu Hospital for the 2017-2018 Period
}

\author{
Vidi Posdo A. Simarmata ${ }^{1}$, Jumaini Andriana Sihombing ${ }^{2}$ \\ ${ }^{1,2}$ Medical Faculty, Universitas Kristen Indonesia, Jakarta, Indonesia \\ Corresponding Author: Vidi Posdo A. Simarmata
}

DOI: https://doi.org/10.52403/ijhsr.20220243

\begin{abstract}
This study aims to determine the patient characteristics and patterns of abnormalities found from Pap Smear examinations at Pasar Minggu Hospital that are useful to reduce the incidence of cervical cancer. This study was a descriptive analysis of content. The number of samples in this study was 62 people by taking data from medical records - the sampling technique using Purposive Sampling. The results showed a diagnosis of PAP Grade II (Inflammation) in 59 people (91.9\%), and a diagnosis of PAP Grade V (Malignancy) is one person (1.6\%).
\end{abstract}

Keywords: Pap Smear, PAP Grade, Characteristics, Cervical Cancer

\section{INTRODUCTION}

Worldwide, there are about 500,000 new cases of cervical cancer and 274,000 deaths caused by cervical cancer each year, making cervical cancer the second most common cause of cancer death in women [1]. Cervical cancer ranks second highest in developing countries, ranks 10th in developed countries and ranks 8th as a cause of death (contributing 3.2\% mortality) globally [2]. Cervical cancer has been ranked second most after breast cancer. There are 530,000 new cases every year, of which $86 \%$ occur in developing countries. Found about 200,000 deaths related to cervical cancer, and 46,000 of them are women aged 15-49 years living in developing countries [3]. According to 2014 data from the Ministry of Health of the Republic of Indonesia, cervical cancer ranks first in the list of cancers suffered by Indonesian women, and its incidence is 90100 per 100,000 population per year, which has been increasing from year to year. The problem of cervical cancer in Indonesia is very distinctive, namely many, and more than $70 \%$ of cases are found at an advanced stage when they come to the hospital [4]. In 2013 alone, there were 98,692 cases of cervical cancer in Indonesia, with the number expected to increase. During 20102013, cervical cancer was one of the third largest diseases at Dharmais Cancer Hospital, Jakarta, where the number of new cases and the number of deaths from cancer continued to increase [5]. In 2016 in Jakarta, women were detected as having cervical cancer, of which most cases were in East Jakarta [6].

The incidence of cervical cancer has decreased by more than $50 \%$ in the last 30 years, mainly due to the increasing use of cervical cancer screening cervical cytology by Pap Test or Pap Smear methods [7]. The cytological screening was invented by George Papanicolaou in the late 1940s and is a significant public health success story in cervical cancer prevention [8]. A Pap smear test is a cytological examination of the cervix and portion to see any changes or 
malignancies in the cervical epithelium or portion (dysplasia) as an early sign of cervical malignancy or precancerous. Pap Smear is a method of examining cells taken from the cervix and then examined under a microscope.

Data from the Indonesian Ministry of Health shows that Pap smear coverage in Indonesia is still low and far from the expected target. Until 2016, only about 1.5 million women from the target of 37 million women aged 30-50 years were screened for cervical cancer. The acetic acid visual inspection (IVA) screening test coverage is only 3.5 per cent, while the Pap Smear is 7.5 per cent. Based on reports from the DKI Jakarta Provincial Health Office in 20152016, Pap smear coverage in Central Jakarta was 784 people $(0.05 \%)$, North Jakarta was 104 people $(0.03 \%)$, West Jakarta was 1,356 people $(0.3 \%)$, South Jakarta was 264 people $(0.07 \%)$, and East Jakarta as many as 1,576 people $(0.33 \%)$ [9]. Because there are still many stigmas, this examination causes discomfort and pain, the cost is rather expensive, and because there is still a lack of socialization about this examination, many people still do not know how important and useful this examination is. So it would be very reasonable if, in Indonesia, many patients are found in advanced cervical cancer due to delays in early detection. The formulation of the problem in this research is "What is the profile of the participants and the pattern of abnormalities in the results of the Pap Smear examination at Pasar Minggu Hospital for the Period of July 2017 - July 2018?" with the aim of the study, namely to find out the distribution description, participant characteristics and abnormal patterns of Pap Smear examination results at Pasar Minggu Hospital from July 2017 to July 2018.

\section{LITERATURE REVIEW}

The cervix is the lowest part of the uterus that protrudes into the upper vagina. The upper part of the vagina ends around the cervix so that the cervix is divided into parts (supravaginal) and lower parts (portion). Anterior to the upper border of the cervix, the internal os, is approximately equal to the peritoneal boundary of the bladder. The cervical canal is fusiform in shape with small holes at both ends. Namely, the internal orifice opens into the uterus and the external orifice, emptying into the vagina [10]. The cervix is innervated by sensory nerves and autonomic nervous systems, both sympathetic and parasympathetic nervous systems. The sympathetic nervous system originates from the T5-L2 region, which sends fibres that synapse in one or many plexuses located on the posterior abdominal wall or in the pelvis so that what reaches the cervix are the postganglionic nerves. Parasympathetic fibres originate in the S2-S4 region and synapse near the plexus or uterine wall. Nerve fibres enter the uterus via the deep cervix and mostly through the Frankenhauser ganglion (cervical ganglion, uterovaginal plexus), which is the main plexus of the pelvis and lies close to the ends of the sacrouterine ligaments [10].

There are physiological changes in the cervical epithelium during a woman's life. The columnar epithelium will be replaced by squamous epithelium, which originates from columnar epithelial reserves. Changing columnar epithelium to squamous epithelium is called the metaplastic process and occurs due to low vaginal $\mathrm{pH}$. High metaplastic activity is often found at puberty. As a result of this metaplasia process, morphogenetically, there are 2 SCJs, namely the original SCJ and the new SCJ, which is the meeting place between the new squamous epithelium and the columnar epithelium. The area between the two SCJs is the transformation zone, which changes with age and during childbirth [11].

Cervical cancer is cancer that occurs in the cervical area, namely the area of the female reproductive organs, which is the entrance to the uterus, located between the uterus (uterus) and the female intercourse hole (vagina) [13]. Cervical cancer ranks second highest in developing countries, 
ranks 10th in developed countries or ranks fifth globally and ranks 8th as a cause of death (contributing $3.2 \%$ mortality) in the world [2]. Cervical cancer has been ranked second most after breast cancer. There are 530,000 new cases every year, of which $86 \%$ occur in developing countries. Found about 200,000 deaths related to cervical cancer, and 46,000 of them are women aged 15-49 years living in developing countries [3]. According to 2014 data from the Ministry of Health of the Republic of Indonesia, cervical cancer ranks first in the list of cancers suffered by Indonesian women, and its incidence is 90-100 per 100,000 population per year, which has been increasing from year to year. The problem of cervical cancer in Indonesia is very distinctive, namely many, and more than $70 \%$ of cases are found at an advanced stage when they come to the hospital [4]. In 2013 alone, there were 98,692 cases of cervical cancer in Indonesia, with the number expected to increase. During 20102013 , cervical cancer was one of the three biggest diseases at Dharmais Cancer Hospital, Jakarta, where the number of new cases and the number of deaths from cancer continued to increase [5]. In 2016 in Jakarta, 823 women were detected as having cervical cancer, of which $50 \%$ were in East Jakarta [6].

The most important aetiology of cervical cancer is closely related to infection with Human Papilloma Virus (HPV), a human carcinogen [13]. HPV infection itself is divided into two based on the potential for malignancy, namely: a) Low-risk types, namely types 6 and 11 associated with anogenital condyloma; and b) High-risk types, namely types 16 and 18 , which are closely related to the incidence of cervical cancer. Type 16 influences as much as 50\% of the incidence of cervical carcinoma, while type 18 only $15 \%$. Meta-analytical studies stated that $2 / 3$ of cervical cancers were associated with 51\% HPV-16 and 16.2\% HPV-18 [12]. HPV can be easily transmitted through sexual activity, and several transmission sources do not depend on penetration but also through skin-to-skin genital contact. Thus, every sexually active woman has a risk for cervical cancer. HPV is an initiating factor for cervical cancer [14]. There are so many risk factors that allow a woman to contract this cancer. These risk factors include age at first sexual intercourse, the number of sexual partners, frequency of pregnancy, age, smoking, and type of contraception $[15 ; 16 ; 17]$.

The discovery of abnormal cells generally characterizes early symptoms of precancerous conditions. Often cervical cancer does not cause symptoms. However, when these abnormal cells develop into cervical cancer, the symptoms of cervical cancer will appear as follows: a) The appearance of pain and bleeding during sexual intercourse (contact bleeding); b) Abnormal vaginal bleeding, such as bleeding outside the menstrual cycle, bleeding between regular menstrual periods, menstrual periods that are longer and heavier than usual, and bleeding after menopause; c) Excessive and abnormal vaginal discharge; d) drastic weight loss; and e) If cancer has spread to the pelvis, the patient will suffer from complaints of pelvic pain, urinary obstruction, and kidney enlargement [14].

Cancer treatment has developed into various treatments: pharmacological therapy, radiotherapy, chemotherapy, hormone therapy, immunotherapy and surgery. However, most cancer patients choose chemotherapy therapy because more and more easily available today to treat cancer. Chemotherapy is a cancer therapy that involves chemicals or drugs that aim to kill cancer cells [16]. However, the main therapy for cervical cancer is surgery and radiation because cervical cancer is gynaecological cancer that is less sensitive to chemotherapy. FIGO recommends standard therapy for cervical cancer with stage IIIB-IVA, external radiation and brachytherapy, concomitant with chemotherapy known as chemoradiation. However, other recommendations say that it is recommended to give neoadjuvant 
chemotherapy, namely therapy with chemotherapy followed by radical hysterectomy. Neoadjuvant chemotherapy is one of the therapeutic strategies for cervical cancer, with radical hysterectomy followed by radiotherapy, concurrent chemoradiotherapy or radiotherapy alone available for the treatment of cervical cancer. It is very important, given that a single therapeutic strategy cannot solve all clinical tumour situations where each tumour presents in a different form [16]. The prognosis for cervical cancer depends on the stage of cancer. At five years of treatment at an early stage has a better prognosis or invasiveness of $92 \%$, a 5-year survival rate overall cervical cancer stage of $72 \%$. Prognosis in cancer that has metastasized to other organs must have a worse prognosis because treatment of local lesions is better than systemic treatment such as chemotherapy. With treatment, 80$90 \%$ of women with stage I cancer and $50 \%-65 \%$ of those with stage II cancer are still alive five years after diagnosis. Approximately $25 \%-35 \%$ of women with stage III cancer and $15 \%$ or more of stage IV cancer are viable after five years [16].

Pap Smear-Test Pap Smear is a cytological examination of the cervix and portion to see any changes or malignancy in the cervical epithelium or portion (dysplasia) as an early sign of cervical malignancy or precancerous. Pap Smear is a method of examining cells taken from the cervix and then examined under a microscope. Pap Smear is a safe and inexpensive test used for many years to detect abnormalities in cervical cells [18]. Pap Smear can detect precursor lesions early so that lesions can be found while therapy may still be curative. The benefits of Pap Smear in detail can be described as follows: a) Early diagnosis of malignancy; b) Pap Smear is useful in early detection of cervical cancer, endometrial corpus cancer, fallopian tube malignancy, and possibly ovarian malignancy; c) Follow-up treatment of malignancy; d) Pap Smear is useful as a follow-up treatment after surgery and after receiving chemotherapy and radiation; e) Interpretation of female hormones; f) Pap Smear aims to follow the menstrual cycle with or without ovulation, determine the maturity of pregnancy, and determine the possibility of miscarriage in early pregnancy; g) Determine the inflammatory process, and h) Pap Smear is useful for determining the inflammatory process in various bacterial and fungal infections.

The Pap test is indicated to screen for malignant and premalignant lesions of the cervix. The recommended age for initiation of cervical cancer screening is 21 years. Previous guidelines recommended starting Pap smear screening three years after the onset of sexual activity or age 21 , whichever occurs first. However, in 2016, this was further revised to recommend that cervical cancer screening be started at age 21, regardless of sexual history [19]. The indications for this Pap Smear examination are all married women who have had sexual intercourse, do not have a history of hysterectomy, do not have any type of cancer, are not pregnant, or have not given birth recently [22].

The American Cancer Society recommends that all women begin screening three years after becoming sexually active [11]. Women who are 30 years of age or older with normal Pap smear results three times have the test again every 2-3 years, except for high-risk women who have to have the test every year. In addition, women who have had a total hysterectomy are not recommended to have a Pap Smear test again. However, women who have had a hysterectomy without cervical removal still need to have a Pap test or other screening according to the recommendations above. Pap smears are not performed during menstruation. The best time to do a Pap Smear is 10-20 days after the first day of the last menstruation [20]. The examination is postponed in patients with severe inflammation until treatment is complete. Two days before the test, the patient was prohibited from washing or using the medication vaginally. It is because the drug 
can affect the results of the examination. The woman is also prohibited from having sexual intercourse for 1-2 days before the Pap Smear examination.

\section{RESEARCH METHOD}

The research was conducted using a descriptive type of document analysis (content analysis), namely by taking secondary medical records from patients who had Pap Smear examinations at once., Jakarta. Time in progress, collection and implementation of research was carried out during September-November 2018. The data used was secondary in medical records from the Pap Smear examinations on the subject. The target population in this study were female patients who underwent Pap Smear examinations. The affordable population in this study was female patients who underwent Pap Smear examinations at the Pasar Minggu Hospital from July 2017 to July 2018. This study used secondary data in medical records of patients who underwent Pap Smear examinations at the Pasar Minggu Hospital in July 2017 - July 2018. The method used in selecting samples to represent the existing population is by using the purposive sampling method, namely the selection of research subjects based on those who meet the inclusion criteria within a predetermined period to be included in the research sample. Data processing is carried out using the SPSS (Statistics Program for Social Science) program for Windows Edition 24.0 and Microsoft Office Excel 2016.

\section{RESULT AND DISCUSSION}

This research occurred at the Laboratory of the Anatomical Pathology Department at Pasar Minggu Hospital under Dr. Reza Aditya Digambiro, M.Kes, M.Ked (PA), Sp.PA, which is located at Jalan TB. Simatupang No.1, RW.01/RW. 05, Ragunan, Sunday Market, South Jakarta. The research sample in this thesis is all patients referred or of their own volition to do a Pap Smear examination. The amount of data that exists and can be used as a sample in the study is 62 people.

Table 1. Distribution of Age Groups when Examined

\begin{tabular}{|l|l|l|}
\hline Age group & Frequency & $\%$ \\
\hline $17-20$ & 1 & 1,6 \\
\hline $21-30$ & 14 & 22,6 \\
\hline $31-40$ & 18 & 29,0 \\
\hline $41-50$ & 21 & 33,9 \\
\hline $51-60$ & 5 & 8,1 \\
\hline$\geq 61$ & 3 & 4,8 \\
\hline Total & 62 & 100,0 \\
\hline
\end{tabular}

Based on age, the results of this study obtained that the largest sample who did Pap Smear examination in the age group $41-50$ years was 21 people $(33.9 \%)$, and the lowest was in the age group 17-20 years as many as one person $(1.6 \%)$. It shows that there is still a lack of knowledge about when to do a Pap Smear examination for the first time because most of those who come to do the examination are of old enough age. Following the Guidelines for the Prevention and Early Detection of Cervical Cancer from the American Cancer Society, the American Society for Colposcopy and Cervical Pathology, and the American Society for Clinical Pathology Screening, age 21 years must have a Pap smear, regardless of sexual history [21].

Table 2. Distribution of Age Groups for the First Time Having Sex

Sex
\begin{tabular}{|l|l|l|}
\hline Age group & Frequency & $\%$ \\
\hline Not filled & 21 & 33,9 \\
\hline $17-20$ & 12 & 19,4 \\
\hline $21-30$ & 27 & 43,5 \\
\hline $31-40$ & 2 & 3,2 \\
\hline $41-50$ & 0 & 0 \\
\hline $51-60$ & 0 & 0 \\
\hline$\geq 61$ & 0 & 0 \\
\hline Total & 62 & 100,0 \\
\hline
\end{tabular}

Based on age, the results of this study obtained the distribution of the age group for the first time having sexual intercourse in the largest sample in the age group 21-30 years as many as 27 people $(43.5 \%)$ and the lowest in the age group 3140 years as many as two people (3.2\%), but 21 people were not identified because they were not entered in the medical record. The highest age is as many as seven people at the age of 25 . It shows that many medical officers ignore this by not conducting interviews or not filling in the medical 
record, even though the age at first having sexual intercourse is one of the risk factors for cervical cancer. This data is also less reliable because it is still taboo to talk to other people in Indonesia, so the validity of this data depends on the patient's level of honesty. However, with this data, we can also conclude that there is no incidence of underage sexual intercourse (under 17 years), and with the large number of patients having sex at the age of 25 years, it can be concluded that many have realized that the age of 21 years and over is the age of the organ. Intimately ready for sexual activity.

Table 3. Clinical Diagnosis
\begin{tabular}{|l|l|l|}
\hline Diagnosis & Frequency & $\%$ \\
\hline Not filled & 4 & 6,5 \\
\hline Want Alone/Initiative & 5 & 8,1 \\
\hline Leukorrhea (abnormal vaginal discharge) & 20 & 32,3 \\
\hline Cervical Polyps & 4 & 6,5 \\
\hline Cervicitis & 4 & 6,5 \\
\hline Ovarian Cyst & 5 & 8,1 \\
\hline Uterine Myoma & 2 & 3,2 \\
\hline IVA history + & 3 & 4,8 \\
\hline Postpartum & 2 & 3,2 \\
\hline MCU (Medical Check-up) & 5 & 8,1 \\
\hline Other & 8 & 12,9 \\
\hline Total & 62 & 100,0 \\
\hline
\end{tabular}

Based on the clinical diagnosis, the results of this study found that the patient did a Pap Smear examination for the most reasons/complaints, namely Leukorrhea (abnormal vaginal discharge) as many as 20 people $(32.3 \%)$, while the reason for the initiative or self-willedness to find out his condition was only four people from total patients $(6.5 \%)$ only. It shows that most patients only have a Pap Smear examination when complaints first arise, and this is not following the existing guidelines, so the purpose of the Pap Smear, which functions as screening, is not achieved [22].

Table 4. Marital Status

\begin{tabular}{|l|l|l|}
\hline Status & Frequency & \% \\
\hline Not filled & 1 & 1,6 \\
\hline Marry & 59 & 95,2 \\
\hline Not married yet & 2 & 3,2 \\
\hline Total & 62 & 100,0 \\
\hline
\end{tabular}

Based on marital status/marriage, the results of this study obtained the largest sample with marital status, namely, Married as many as 59 people $(95.2 \%)$ and Unmarried as many as two people (3.2\%).
This data should be studied more deeply about when to have sex for the first time and when to get married because these two things have different points but have an attachment.

Table 5. Number of Sexual Partners

\begin{tabular}{|l|l|l|}
\hline Table 5. Number of Sexual Partners \\
\begin{tabular}{|l|l|l|}
\hline Number & Frequency & $\%$ \\
\hline Not filled & 17 & 27,1 \\
\hline One person & 42 & 67,7 \\
\hline$>1$ person & 3 & 4,8 \\
\hline Total & 62 & 100,0 \\
\hline
\end{tabular}
\end{tabular}

Based on the number of sexual partners, the results of this study obtained that the highest sample had a sexual partner of 1 person, namely 42 people $(67.7 \%)$ and the number of sexual partners $>1$ person, namely three people (4.8\%), but 17 people not identified because it is not filled in the medical record. It shows that many medical officers ignore this by not conducting interviews or not filling in the medical records, even though the number of sexual partners for the first time having sexual intercourse is one of the risk factors for cervical cancer. This data is also less reliable because it is still taboo to talk to other people in Indonesia, so the validity of this data depends on the patient's level of honesty. However, with this data, we can conclude that almost half of the patients only have one sexual partner, reducing the incidence of cervical cancer.

Table 6. Total Parity
\begin{tabular}{|l|l|l|}
\hline Number & Frequency & $\%$ \\
\hline Not filled & 18 & 29,0 \\
\hline Never (Nullipara) & 8 & 12,9 \\
\hline 1 person (Primipara) & 10 & 16,1 \\
\hline 2-4 people (Multipara) & 19 & 30,6 \\
\hline$>5$ people (Grandemultipara) & 7 & 11,3 \\
\hline Total & 62 & 100,0 \\
\hline
\end{tabular}

Based on the number of parties, the results of this study obtained that the highest sample had parity of 2-4 people (Multipara) as many as 19 people $(30.6 \%)$ and the lowest number of parity $>5$ people (Grandemultipara) as many as seven people $(11.3 \%$ ). However, 18 people were not identified because they were not entered into the medical record. It shows that there are still many medical officers who ignore this by not conducting interviews or not filling in the medical records, even though 
the number of parity is one of the risk factors for cervical cancer shows that the stigma of having many children with lots of fortune is no longer valid nowadays. From this data, we can evaluate that family planning programs in Indonesia are good enough to reduce the incidence of cervical cancer.

Table 7. Types of Family Planning Program

\begin{tabular}{|l|l|l|}
\hline Number & Frequency & \% \\
\hline Not filled & 29 & 46,8 \\
\hline Not Using KB & 6 & 9,7 \\
\hline Pill & 6 & 9,7 \\
\hline Inject & 7 & 11,3 \\
\hline Implant & 1 & 1,6 \\
\hline Spiral/IUD & 10 & 16,1 \\
\hline Sterile & 3 & 4,8 \\
\hline Total & 62 & 100,0 \\
\hline
\end{tabular}

Based on the type of family planning used, the results of this study obtained that the highest sample used the Spiral/IUD (Intra Uterine Device) type of contraception, as many as ten people $(16.1 \%)$ and the lowest with the use of implants as many as one person $(1.6 \%)$. It shows that IUD contraceptives are more desirable because they are more efficient, do not cause obesity side effects, and do not need obedience in use because it is only installed once. With many patients using this type of IUD can reduce the incidence of cervical cancer because it does not affect the hormonal balance in the body and does not cause injury, which can be a good place for HPV infection [23].

Table 8. Pap Smear Cytological Overview of General Categories

\begin{tabular}{|l|l|l|}
\hline \multicolumn{1}{|c|}{ Types } & Frequency & \% \\
\hline $\begin{array}{l}\text { NILM (Negative for Intraephitelial } \\
\text { Malignant Lesion) }\end{array}$ & 60 & 96,8 \\
\hline Endometrial cells >40 years & 0 & 0 \\
\hline Epithelial Cell Abnormal & 2 & 3,2 \\
\hline Total & 62 & 100,0 \\
\hline
\end{tabular}

Based on the cytological description of the Pap Smear examination, interpretation can be made through three classes/systems, namely the General Category, Papanicolaou Class, and/or the Bethesda System. The results of this study obtained a cytological picture of samples according to the general category system, the most in the NILM (Negative Intraepithelial Lesson Malignant) category as many as 60 people $(96.8 \%)$ and the lowest in the Abnormal epithelial cell category as many as two people $(3.2 \%)$. It shows that almost all examined patients did not experience significant changes towards cervical malignancy.

Table 9. Cytological description of Pap Smear in Papanicolaou Class

\begin{tabular}{|l|l|l|}
\hline Types & Frequency & $\%$ \\
\hline PAP Grade I (Normal/Atrophic Smear) & 3 & 4,8 \\
\hline PAP Grade II (Inflammation) & 57 & 91,9 \\
\hline PAP Grade III (mild/moderate dysplasia) & 1 & 1,6 \\
\hline PAP Grade IV (Hard Dysplasia/Ca.In Situ) & 0 & 0 \\
\hline PAP Grade V (malignant) & 1 & 1,6 \\
\hline Total & 62 & 100,0 \\
\hline
\end{tabular}

Based on the Papanicolaou system/class, the results of this study obtained the largest sample with the interpretation of PAP Grade II (Inflammation) as many as 57 people $(91.9 \%)$ and the lowest PAP Grade III (mild/moderate dysplasia) and Grade V (malignant) respectively. Each has as many as one person $(1.6 \%)$. It shows that almost all the patients examined showed inflammation results without significant cell changes leading to malignancy, and this is a good sign that the expected result is not a malignancy, so the main goal of Pap Smear as a screening method can work and follow. The existing guidelines state that this Pap Smear examination must be repeated every year depending on the findings of abnormalities and the doctor's recommendation for conducting the examination [24].

Table 10. Cytological Overview of Bethesda Class Pap Smears

\begin{tabular}{|l|l|l|}
\hline Types & Frequency & $\mathbf{\%}$ \\
\hline Not filled & 56 & 90,3 \\
\hline Organism: Fungal Candida spp & 2 & 3,2 \\
\hline Organism: Bacterial Vaginosis & 1 & 1,6 \\
\hline Organism: Herpes Simplex Virus & 1, & 1,6 \\
\hline ASCUS & 0 & 0 \\
\hline ASCH & 0 & 0 \\
\hline LGSIL & 1 & 1,6 \\
\hline HGSIL & 0 & 0 \\
\hline Squamous Cell Carcinoma & 1 & 1,6 \\
\hline Total & 62 & 100,0 \\
\hline
\end{tabular}

Based on the Bethesda system/class, the results of this study obtained the largest sample with the interpretation results not filled in by a doctor as many as 56 people (90.3\%), Organisms: Fungal candida spp as many as two people (3.2\%) and Organisms: 
Bacterial Vaginosis; Herpes Simplex Virus; LGSIL; Squamous Cell Carcinoma with each as many as one people (1.6\%). Almost all data is not filled in, which can happen depending on what system/class the Anatomical Pathology specialist is using. From the available data, the Department of Anatomical Pathology at Pasar Minggu Hospital interprets the Pap Smear examination using the General Category system/class and Papanicolaou.

Description of the Distribution of Clinical Diagnosis by Age Group when examined-based on the table above, it can be seen that the most common clinical cause of causing patients to undergo Pap Smear examinations is Leukorrhea, which occurs in almost all age groups, and the age group that suffers the most complaints is the age group. 31-40 years as many as six people. Following the theory discussed in the literature review that at productive age/fertile age, the vagina and cervix, which have epithelial/squamous cells that function to coat and lubricate the area, can be very sensitive at productive age/fertile age in normal conditions, good bacteria/normal flora exists. Its existence can be disrupted due to lifestyle, hormonal situation, sexual activity and injuries due to childbirth. And the body's way of defending itself is by secreting an abnormal vaginal discharge that becomes one of the clinical manifestations of inflammation in the area. So it is very well known that complaints of Leukorrhea will be the most common complaint experienced by women, so they are referred for a Pap Smear examination. However, what is unfortunate is that the average patient does an examination not because a complaint/referral has arisen, even though this Pap Smear examination should be an obligation for every woman who has had sexual intercourse.

Distribution description of Papanicolaou Class Cytological Picture with Clinical Diagnosis- based on the table above can be seen that the interpretation of Pap Smear examination results from Papanicolaou class, namely PAP Grade II
(Inflammation), which is the most interpretation of patients can be caused by almost all clinical diagnoses or complaints, and the most because of Leukorrhea as many as 19 people. It proves that the inflammatory process in the cervical area can be caused by many factors and can cause different clinical manifestations/complaints. With many determinations of the Grade II PAP examination results, it shows that the screening function of the Pap Smear examination is successful because many have been detected early so that further action can be determined.

Distribution description of Papanicolaou Class Cytological Figure with Total Parity Based on the table above shows that in the interpretation of the Pap Smear examination results for the Papanicolaou class, PAP Grade II (Inflammation) can be experienced by all groups with the number of existing parties. However, the highest is found in the group. The number of parity 24 people (Multiparity). In theory, discussed in the literature review, parity is one of the risk factors that can affect the possibility of cervical cancer. These results are in line with the research who found that $58.5 \%$ of cervical cancer patients were multiparous, and proved that the Pap Smear examination was classified as good because it was sensitive to find the possibility of getting sick according to the theory. However, other factors affect the results of this study, such as medical personnel who do not fill in the parity number in the medical record so that the comparison of the percentage who does not fill the parity number with the multipara sample is the same and makes the results less good for analysis, the delay factor in screening, and the number factor. The largest sample with the number of parity is multipara, so it can affect the study results.

The distribution of interpretations of the Papanicolaou Class Cytological description with the age group when examined based on the table above can be seen that the Pap Smear examination results for the Papanicolaou class. Namely, PAP 
Grade II (Inflammation) can be experienced by all age groups when examined, and the most, namely the age group 41-50 years, as many as 20 people because according to the number of samples they are in that age group. The diversity of this age group is influenced by several factors such as lifestyle, delay in screening time, body immunity, number of sexual partners, number of parity, and others.

The description of the distribution of parity numbers by age group when examined based on the table above, it can be seen that the age group that performs the most Pap Smear examinations is 41-50 years of age who have parity status or the number of 2-4 people (Multipara). It is in line with the description of the characteristics of the age section of the sample, which states that the 41-50-year age group has the most Pap Smear examinations, thus affecting the presence of multipara parity in this study. From this data, we can also conclude that the patients who underwent Pap Smear examinations at Pasar Minggu Hospital had entered a too late age, namely 41-50 years, so many factors could influence the interpretation results.

Description of the distribution of family planning types with the interpretation of the Papanicolaou Class Cytology description - based on the table above, we can see that the type of family planning is one of the risk factors for the possibility of cervical cancer and is still being forgotten or ignored by much medical personnel who do not fill in this information in the records. There are 28 medical patients, so the results of this study cannot be analyzed for their influence on the results of the Pap Smear examination. From the graph above, it can be concluded that many samples prefer to use the Spiral or IUD because it is more practical, its use will not be forgotten, and it does not cause side effects of changes in body weight so that its use is more than the cheaper pills but requires compliance in its use and finally the success of family planning more reduced. However, in PAP
Grade III, the research results follow the theory that the type of birth control pill used affects the presence/condition of the hormone estrogen in women to increase the risk of cervical cancer.

\section{CONCLUSION}

Based on the results of the analysis and discussion of the research, the following conclusions can be drawn: a) There is still a lack of education/knowledge/information by health facilities or medical personnel about Pap Smear examinations, for example, at any time a Pap Smear examination should be carried out because of the age trend. Those who came for Pap Smear examination for the first time at Pasar Minggu Hospital are 41-50 years as many as 20 people $(33.9 \%)$. This age was too late from the existing guidelines and the rules set by WHO; b) There is still a lack of provision or education/knowledge/ information counselling by health facilities or medical personnel about Pap Smear examinations. For example, a Pap Smear examination should be carried out because the existing trend shows that new samples come/are referred for a Pap Smear examination after experiencing a Pap smear. Complaints or get a clinical diagnosis first. Complaints/clinical diagnoses that most indicated a Pap smear examination were Leukorrhea with 21 samples $(32 \%)$; c) There is still a lack of education/ knowledge/information for medical personnel about the importance of completeness of medical information records before carrying out Pap Smear examinations. Because of the study results, many variables were not filled in by health workers, which affected the analysis process. Reducing this incidence was not achieved due to lack of information about risk factors contained in the patient's medical record; d) The use of the system/class for interpretation depends on what system is adopted by the existing Anatomical Pathology specialist. There were many patterns of abnormality/ interpretation of Pap Smear examination 
results for Papanicolaou class, namely PAP Grade II (Inflammation) as many as 57 people $(91.9 \%)$ and interpretation of Pap Smear examination results in the general category of NILM (Negative Intraepithelial Lesion Malignant) as many as 60 people (96.8 \%); e) There are no special Pap Smear examination questionnaires that can meet the patient's information needs that are useful for further action, and f) Pap Smear examination has good sensitivity and specificity and satisfactory results because almost $96 \%$ of interpretations of Pap Smear examination results from Papanicolaou class cytology results provide PAP Grade II (Inflammation) results so that the main purpose of Pap Smears is to screen and detect precancerous lesions early achieved.

\section{Acknowledgement: None}

\section{Conflict of Interest: None}

\section{Source of Funding: None}

\section{Ethical Approval: Approved}

\section{REFERENCES}

1. World Health Organization. Cervical cancer, human papillomavirus (HPV) and $H P V$ vaccines: Key points for policy-makers and health professionals. No. WHO/RHR/08.14. World Health Organization, 2008.

2. Bray, Freddie, Jacques Ferlay, Isabelle Soerjomataram, Rebecca L. Siegel, Lindsey A. Torre, and Ahmedin Jemal. "Global cancer statistics 2018: GLOBOCAN estimates of incidence and mortality worldwide for 36 cancers in 185 countries." CA: a cancer journal for clinicians 68 , no. 6 (2018): 394-424.

3. Jones-Williams, Carol. "A Comparative Study of Cervical Cancer Among Indigenous Amerindian, Afro-Guyanese, and Indo-Guyanese Women in Guyana." PhD diss., Walden University, 2017.

4. Widia, Fina, Muhammad Firman, Gampo Alam Irdam, and Ridho Ardhi Syaiful. "A six years' experience with 41 cases of enterovesical fistula in a Tertiary National Hospital in Indonesia: A retrospective study." Annals of Medicine and Surgery 73 (2022): 103102.

5. Kabuhung, Elvine Ivana, Eka Sapitri, and Fadhiyah Noor Anisa. "Related Factors With Breast Cancer Cases In Women At Ulin Hospital Banjarmasin." (2017): 487494.

6. Hartati, Suryani, and Retno Winarti. "Mother's knowledge level about cervical cancer in East Jakarta area." Enfermeria clinica 30 (2020): 108-112.

7. Johnson, Janice L. "Screening for Cervical Cancer and Management of Its Precursor Lesions." In Ambulatory Gynecology, pp. 147-162. Springer, New York, NY, 2018.

8. Högnäs, Emma, Antti Kauppila, Marianne Hinkula, Juha S. Tapanainen, and Eero Pukkala. "Incidence of cancer among grand multiparous women in Finland with special focus on non-gynaecological cancers: A population-based cohort study." Acta Oncologica 55, no. 3 (2016): 370-376.

9. Apgar, Barbara S., Gregory L. Brotzman, and Mark Spitzer. Colposcopy E-Book: Principles and Practice. Elsevier Health Sciences, 2008.

10. Kale, Ahmet, Gulfem Basol, Taner Usta, and Hande G. Aytuluk. "Laparoscopic evaluation of female pelvic neuroanatomy and autonomic plexuses in terms of gynecologic perspective." Journal of Endometriosis and Pelvic Pain Disorders 10, no. 4 (2018): 216-221.

11. Aina, Oluwatomisin E., Steve A. Adeshina, and A. M. Aibinu. "Deep learning for image-based cervical Cancer detection and diagnosis - a survey." In 2019 15th International Conference on Electronics, Computer and Computation (ICECCO), pp. 1-7. IEEE, 2019.

12. Fontham, Elizabeth TH, Andrew MD Wolf, Timothy R. Church, Ruth Etzioni, Christopher R. Flowers, Abbe Herzig, Carmen E. Guerra et al. "Cervical cancer screening for individuals at average risk: 2020 guideline update from the American Cancer Society." CA: A Cancer Journal for Clinicians 70, no. 5 (2020): 321-346.

13. Darwati, Lilik, and Khusnul Nikmah. "The Relationship Between Educational Factors and Early Detection Behavior Cervical $\mathrm{Ca}$ in Fertile Age Women." STRADA Jurnal Ilmiah Kesehatan 9, no. 2 (2020): 14811488. 
14. American College of Obstetricians and Gynecologists. "ACOG practice bulletin. Clinical management guidelines for obstetrician-gynecologists. Number 61, April 2005. Human papillomavirus." Obstetrics and gynecology 105, no. 4 (2005): 905-918.

15. Kjellberg, L., G. Hallmans, A. M. Åhren, R. Johansson, F. Bergman, G. Wadell, T. Ångström, and J. Dillner. "Smoking, diet, pregnancy and oral contraceptive use as risk factors for cervical intra-epithelial neoplasia in relation to human papillomavirus infection." British journal of cancer 82, no. 7 (2000): 1332-1338.

16. Darragh, Teresa M., Terence J. Colgan, J. Thomas Cox, Debra S. Heller, Michael R. Henry, Ronald D. Luff, Timothy McCalmont et al. "The lower anogenital squamous terminology standardization project for HPV-associated lesions: background and consensus recommendations from the College of American Pathologists and the American Society for Colposcopy and Cervical Pathology." Archives of pathology \& laboratory medicine 136, no. 10 (2012): 1266-1297.

17. Khan, Michelle J., Claudia L. Werner, Teresa M. Darragh, Richard S. Guido, Cara Mathews, Anna-Barbara Moscicki, Martha M. Mitchell et al. "ASCCP colposcopy standards: role of colposcopy, benefits, potential harms, and terminology for colposcopic practice." Journal of lower genital tract disease 21, no. 4 (2017): 223229.

18. Abbas, A. K., J. C. Aster, and V. Kumar. "Buku Ajar Patologi Robbins." Edisi9. Singapura: Elsevier Saunders (2015).

19. Moyer, Virginia A. "Screening for cervical cancer: US Preventive Services Task Force recommendation statement." Annals of internal medicine 156, no. 12 (2012): 880891.

20. American College of Obstetricians and Gynecologists. "Abnormal Cervical Cancer
Screening Results. January 2016." URL: https://www. acog. org/-/media/ForPatients/faq187. pdf? dmc= $1 \& t s=20190$ $822 T 2244488293$ (дата обращения22.08. 2019).

21. Saslow, Debbie, Diane Solomon, Herschel W. Lawson, Maureen Killackey, Shalini L. Kulasingam, Joanna Cain, Francisco AR Garcia et al. "American Cancer Society, American Society for Colposcopy and Cervical Pathology, and American Society for Clinical Pathology screening guidelines for the prevention and early detection of cervical cancer." CA: a cancer journal for clinicians 62, no. 3 (2012): 147-172.

22. Saleh, Hend S. "Can visual inspection with acetic acid be used as an alternative to Pap smear in screening cervical cancer?." Middle East Fertility Society Journal 19, no. 3 (2014): 187-191.

23. Saslow, Debbie, Diane Solomon, Herschel W. Lawson, Maureen Killackey, Shalini L. Kulasingam, Joanna Cain, Francisco AR Garcia et al. "American Cancer Society, American Society for Colposcopy and Cervical Pathology, and American Society for Clinical Pathology screening guidelines for the prevention and early detection of cervical cancer." CA: a cancer journal for clinicians 62, no. 3 (2012): 147-172.

24. Wong, L. P., Y. L. Wong, W. Y. Low, E. M. Khoo, and R. Shuib. "Knowledge and awareness of cervical cancer and screening among Malaysian women who have never had a Pap smear: a qualitative study." Singapore medical journal 50, no. 1 (2009): 49.

How to cite this article: Vidi Posdo A. Simarmata, Jumaini Andriana Sihombing. Patient characteristics profile and pap smear examination results at Pasar Minggu Hospital for the 2017-2018 period. Int J Health Sci Res. 2022; 12(2): 329-339. DOI: https://doi.org/ 10.52403/ijhsr.20220243 